\title{
CURCUMINA COMO INDICADOR NATURAL DE PH: UMA ABORDAGEM TEÓRICA-EXPERIMENTAL PARA O ENSINO DE QUÍMICA
}

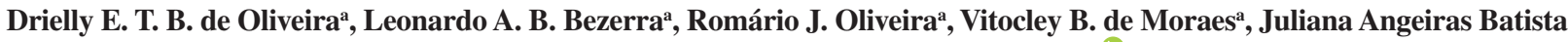
da Silva ${ }^{\text {a,b }}$, João R. de Freitas Filho ${ }^{a}$, Juliano C. Rufino Freitas ${ }^{\text {a,c }}$ e Clécio S. Ramos ${ }^{\text {a,*,(i) }}$

aDepartamento de Química, Universidade Federal Rural de Pernambuco, 52171-900 Recife - PE, Brasil

${ }^{\mathrm{b} C e n t r o ~ A c a d e ̂ m i c o ~ d o ~ A g r e s t e, ~ U n i v e r s i d a d e ~ F e d e r a l ~ d e ~ P e r n a m b u c o, ~ 55002-970 ~ C a r u a r u ~-~ P E, ~ B r a s i l ~}$

${ }^{c}$ Centro de Educação e Saúde, Universidade Federal de Campina Grande, 58175-000 Cuité - PB, Brasil

CURCUMINE AS A NATURAL PH INDICATOR: AN EXPERIMENTAL THEORETICAL APPROACH FOR CHEMICAL TEACHING. This paper proposes the development of a simple experiment with easily accessible and low cost materials, enabling its practice with or without laboratory infrastructure, with feasibility for computational theoretical study. On the other hand, the objective of the work is to develop a chemical experiment that demonstrates that the chromophore curcumin (natural indicator) is responsible for indicating the acidity or basicity of a given solution. The experiment has different applicability, being useful in the approach of different chemical contents, showing potential for multi and interdisciplinary approaches. Subjects such as tautomeric equilibrium, chromophoric compounds, hydrogen potential, UV-Vis electron absorption spectra analysis and molecular modeling are explored.

Keywords: chromophore; curcumin; UV-Vis spectroscopy; theoretical study.

\section{INTRODUÇÃO}

A experimentação, no geral, é considerada como uma estratégia de ensino fundamental no processo de ensino e da aprendizagem das ciências nas instituições de ensino. Desse modo, a atividade experimental é tratada pelos docentes como parte essencial no que diz respeito a ser "um docente de ciências". Tratando de uma abordagem diferenciada de ensino e ambiente de aprendizagem, a experimentação pode e tem sido utilizada com uma gama de possibilidades, fundamentadas no alcance de metas ou objetivos dos professores, bem como das escolas e universidades. ${ }^{1}$ Em 2015, Cunha e colaboradores ${ }^{2}$ relataram a síntese de ácidos 3-cumarinacarboxílicos em experimento de graduação em química orgânica. Em 2012, encontramos na literatura um artigo que descreve um experimento de graduação para a síntese do aduto de Knoevenagel do ácido de Meldrum, usando água como solvente. ${ }^{3}$

A relevância da experimentação no ensino de química é demonstrada pelo crescente número de publicações e citações envolvendo o tema "experimentation in chemistry teaching" ${ }_{4}^{4}$ nos mais diversos periódicos científicos, como observado nos gráficos
A (número de publicações) e B (número de citações) conforme mostrados na Figura 1. A pesquisa foi realizada no banco de dados da Scielo, Web Of Science, SciFinder e também no Portal de Periódicos da CAPES.

A utilização do conceito de $\mathrm{pH}$ no ensino de química, especificamente no que diz respeito aos indicadores naturais de pH é uma perspectiva que nos últimos anos vem sendo relatada em diversos trabalhos. ${ }^{5-10}$ Devido à praticidade nas medições de $\mathrm{pH}$, esse tipo de abordagem pode ser facilmente aplicada em inúmeras aulas experimentais visando trabalhar diversas conteúdos de química. Estudos relacionados às práticas laboratoriais envolvendo a utilização de indicadores naturais já foram realizados e demonstram a relevância da relação da experimentação e a possibilidade da aprendizagem de conceitos químicos. ${ }^{11-16}$ Esses estudos normalmente estão fundamentados dentre outros fatores, na determinação de $\mathrm{pH}$ utilizando indicadores derivados de plantas, não havendo, no entanto, nenhum estudo relacionado ao fato de demonstrar de forma simples e didática quais são os compostos que dão cores às plantas (os cromóforos), e quais são os responsáveis por essa indicação observada na forma de mudança de coloração em meio ácido, neutro ou básico.
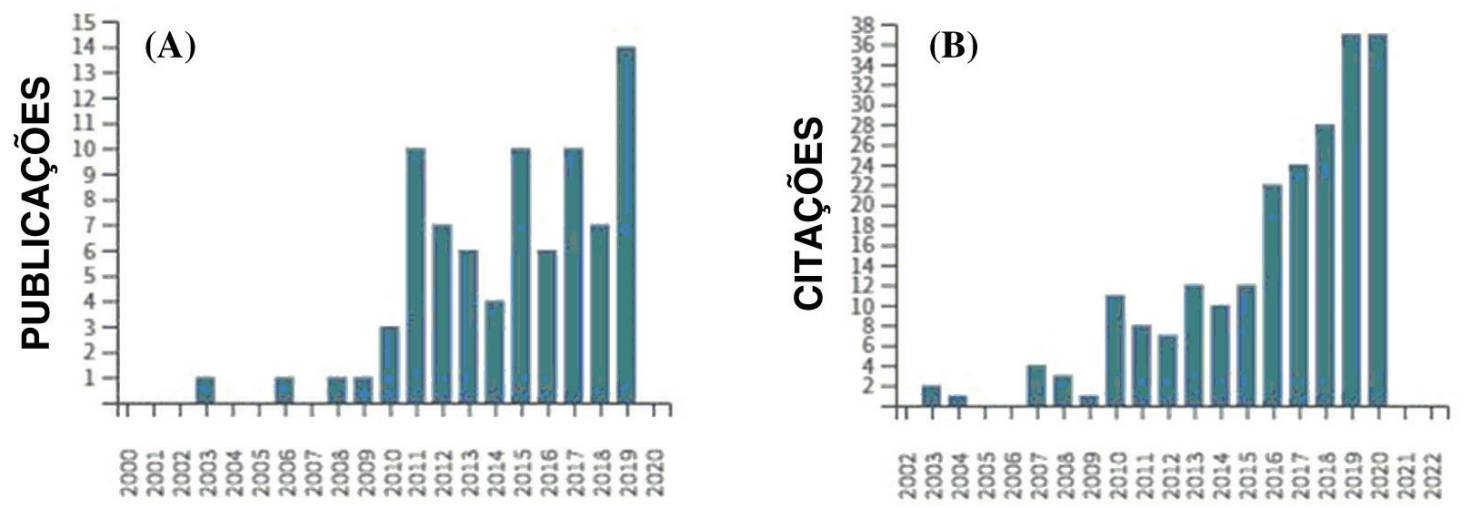

Figura 1. Número de publicações e citações envolvendo o tema "experimentation in chemistry teaching”

*e-mail: csramos13@hotmail.com 
No âmbito da química dos produtos naturais, a Cúrcuma (açafrãoda-terra), condimento de cor amarelo derivado da Curcuma longa, possui diversas propriedades relacionadas ao campo biológico, tais como, atividades antioxidante, antitumoral, anti-inflamatória, antiviral, antibacteriana, antifúngica, antimalárica, leishmanicida, além de combater a doença de Alzheimer e, potencialmente, o HIV. ${ }^{17}$ Estudos mostram que essas propriedades, além da coloração amarelada, estão associadas à curcumina (1), composto majoritário da Cúrcuma, ${ }^{18,19}$ que pode existir na forma dos tautômeros (1a, 1b e 1c - Figura 2) em equilíbrio, de modo que trabalhos teóricos apontam a predominância da forma ceto-enólica (1a). ${ }^{20-23}$ Outra propriedade interessante da curcumina é a mudança de coloração de acordo com a acidez ou basicidade do meio. Existe a predominância da coloração avermelhada quando em solução básica, ou seja, quando ocorre retirada de prótons ácidos da estrutura da curcumina; e coloração amarelada quando em meio ácido e neutro. ${ }^{24,25}$ Desse modo, a curcumina, além de ser uma molécula biologicamente ativa é um indicador natural de ácido-base, podendo ser aplicado em aulas práticas tanto na educação básica quanto no ensino superior.

Muitos produtos naturais produzem indicadores naturais de acidez e basicidade. ${ }^{26}$ A curcumina é uma molécula de fácil acesso, tanto pelo isolamento da matriz natural quanto pela síntese total. Possui expressiva atividade em uma série de modelos biológicos in vitro, com as mais variadas aplicações. ${ }^{27}$ Por outro lado, a curcumina, que pode ser utilizada como um indicador de $\mathrm{pH}$, apresenta uma coloração amarela em solução ácida $(\mathrm{pH}<7,4)$ e uma coloração vermelha em solução básica $(\mathrm{pH}>8,6) .{ }^{28}$ Patil et al. ${ }^{29}$ utilizaram uma solução extraída de rizomas de Curcuma longa (açafrão) como um indicador de titulação. Os autores também fizeram um estudo comparativo entre Curcuma longa, um indicador natural, com um indicador sintético, por exemplo, a fenolftaleína e o laranjado de metila e obtiveram resultados semelhantes. Outros trabalhos relevantes também destacam as aplicações da curcumina como indicador de ácido e bases. ${ }^{30-33}$

De acordo com Fagundes et al.,${ }^{34}$ os pigmentos de açafrão foram usados para ensinar extração contínua ou descontínua, destilação a vácuo ou sob pressão atmosférica e cromatografia em camada fina (TLC, do inglês thin-layer chromatography) em um curso introdutório de laboratório de química orgânica. Além da extração, uso como indicador ácido-base e aplicações da curcumina, também há relato da determinação de espectro de absorção molecular de UV-Vis. Em 2018, Supharoek e colaboradores ${ }^{35}$ empregaram reagentes de extrato natural (açafrão) para determinação de ácido acético após uma reação de ácido-base em presença de um indicador. O método foi aplicado com sucesso para testar a concentração de ácido acético em amostras de vinagre de cozinha. No trabalho, os autores também relataram que a<smiles>COc1cc(/C=C/C(=O)/C=C(O)/C=C/c2ccc(O)c(OC)c2)ccc1O</smiles>

$1 \mathrm{a}$ solução de açafrão extraída absorveu a luz visível a $420 \mathrm{~nm}$. Uma cor laranja e/ou marrom avermelhado foi obtida após a mistura da solução de açafrão (indicador) com a solução de cal (base), que forneceu o comprimento de onda máximo a $455 \mathrm{~nm}$. A absorvância a $455 \mathrm{~nm}$ diminuiu com o aumento da concentração de ácido acético, porque o ácido acético reagiu com o íons hidróxidos na solução, resultando em uma alteração de $\mathrm{pH}$, com a cor da solução mista alterando de laranja e/ou marrom avermelhado para amarelo.

Partindo desses pressupostos, o diferencial da proposta de experimentação aqui apresentada está na identificação dos cromóforos responsáveis por proporcionar as mudanças de cores em meio ácido ou básico das soluções em que estão contidos e o uso de cáculos computacionais para modelar o espectro UV-Vis da Curcumina no equilíbrio ceto-enólico. Portanto, o objetivo deste estudo é desenvolver um experimento químico que demonstre qual cromóforo curcumina (indicador natural) é responsável pela indicação da acidez ou basicidade de determinada solução.

\section{PARTE EXPERIMENTAL}

\section{Materiais e equipamentos}

Para a realização do experimento foi necessário o uso de equipamentos de proteção individual: luvas, óculos de segurança e jaleco. Como vidrarias e utensílios de laboratório foram utilizados: béquer, tubo de ensaios, erlenmeyer, espátulas, pinça, balança analítica, pipeta, pisseta e bastão de vidro. As substâncias necessárias para a preparação e uso do indicador foram: açafrão, etanol, carvão ativado, papel de filtro, vinagre (ácido acético), água destilada e bicarbonato de sódio. As amostras das soluções 01 e 02 , bem como das soluções ácida e básica com adição do indicador foram analisadas por espectrofotometria de absorção molecular no UV-Vis (Shimadzu - UV 1900) na região entre 350 a $700 \mathrm{~nm}$ para determinação do comprimento de onda de máxima absorção $\left(\lambda_{\mathrm{m}}\right)$ das amostras, utilizando cubetas de quartzo.

\section{Procedimentos}

O experimento compreendeu quatro etapas, descritas a seguir.

\section{Primeira etapa: preparação do indicador ácido-base}

Em um béquer, preparou-se a solução do indicador ácido-base. Solubilizou-se $1 \mathrm{~g}$ de açafrão em pó em $100 \mathrm{~mL}$ de etanol $70 \%$. Com o auxílio de um bastão de vidro a solução do indicador foi homogeneizada. Em seguida esta solução foi dividida em duas partes,<smiles>COC1=CC(=CC=C(O)C=C(O)C=Cc2ccc(O)c(OC)c2)C=CC1=O</smiles> 
solução 01 e solução 02 , de $50 \mathrm{~mL}$ cada. A solução 01 foi reservada. Adicionou-se carvão ativado à solução 02 que posteriormente foi agitada e na sequência deixada em repouso até que o carvão em solução decantasse. Em seguida, realizou-se uma filtração em papel filtro para remoção dos resíduos insolúveis. Repetiu-se o processo de adição do carvão ativado e posterior filtração, três vezes até que a solução 02 ficasse incolor.

\section{Segunda etapa: teste do indicador ácido-base}

Por fim, utilizou-se vinagre $(\mathrm{pH}=2)$ como solução ácida, e preparou-se a solução básica de bicarbonato de sódio comercial $\left(\mathrm{NaHCO}_{3} 0,5 \mathrm{~mol} \mathrm{~L}^{-1}-\mathrm{pH}=9\right)$ para realização do teste de indicação ácido-base. Após o preparo de todas as soluções, a prática foi dividida em duas partes, A e B.

Parte A: Teste de indicação utilizando gotas da solução 01, adicionadas às soluções ácida e básica. Parte B: Teste de indicação utilizando gotas da solução 02 , adicionadas às soluções ácida e básica. A Figura 3 ilustra o experimento.

Na Tabela 1, estão listados alguns materiais convencionais e alternativos que podem ser empregados também na realização do experimento.

Tabela 1. Materiais alternativos que podem ser usados no experimento

\begin{tabular}{cc}
\hline Materiais Convencionais & Materiais alternativos \\
\hline Tubos de ensaio & Copos transparentes \\
Pipetas Pasteur & Seringas ou conta-gotas \\
Espátulas / bastão de vidro & Colheres \\
Solução ácida & Suco de limão, ácido muriático, \\
refrigerante etc.
\end{tabular}

\section{Terceira etapa: espectrofotometria de absorção molecular no} UV-Vis

Os espectros de absorção molecular foram previamente obtidos por espectrofotometria de acordo com o procedimento: utilizou-se as amostras das soluções 01 e 02 , bem como das soluções ácida e básica com adição do indicador. Enche-se uma cubeta (quartzo) com uma das amostras e outra com a solução de referência (branco). Em seguida, registra e anota o espectro (Absorbância x $\lambda(\mathrm{nm})$ ), com resolução de $20 \mathrm{~nm}$ e na faixa de $350-700 \mathrm{~nm}$. Nesta etapa, identificar no espectro o comprimento de onda de máxima absorção.

\section{Quarta etapa: cálculo computacional}

A metodologia computacional utilizada se baseia na teoria do funcional de densidade (DFT, do inglês Density Functional Theory) que utiliza funcionais de densidade eletrônica como métodos de aproximação para resolver a equação de Schrodinger não-relavística e independente do tempo para sistemas multi-eletrônicos. ${ }^{36}$ Para modelar o espectro UV-Vis da Curcumina no equilíbrio ceto-enólico, foram realizados cálculos de otimização de geometria e frequência com o funcional híbrido B3LYP (Becke 3-parameter Lee-YangParr $)^{37}$ e o conjunto de funções de base de Pople, ${ }^{38,39} 6-31+g(d)$. A modelagem computacional foi feita em solução aquosa com o método de solvatação do contínuo dielétrico SMD. ${ }^{40}$ No entanto, cálculos de espectroscopia não utilizam sistemas em estado fundamental, sendo necessário realizar cálculos de estado excitado. Para isso, a metodologia TD-DFT (TD, do inglês Time Dependent $)^{41,42}$ foi empregada. Softwares de Química computacional como Gauss View ${ }^{43}$ e Gaussian ${ }^{44}$ foram utilizados na montagem das moléculas e nos cálculos. Outros programas, tais como WebMol e Gammes, ${ }^{45}$ são bastante versáteis para a modelagem de espectros de sistemas orgânicos e inorgânicos e são conhecidos no universo acâdemico, dentro do âmbito da Química Computacional.

\section{Tratamento dos dados}

Os espectros obtidos a partir do estudo teórico e dos dados da espectroscopia de absorção eletrônica UV-Vis foram gerados utilizando o software OriginPro 8.

\section{Conteúdos aplicados e estratégias de ensino}

As estratégias de ensino utilizadas foram a aula expositivadialogada e a experimentação. Estas foram desenvolvivas nas aulas da disciplina de Tópicos Especiais em Química na Pós-graduação em Química durante um semestre. Os conteúdos estudados durante a aula expositiva-dialogada e experimental foram: ácidos, bases, indicadores, equilíbrio iônico da água (conceito de $\mathrm{pH}$ e escala de $\mathrm{pH}$ ), espectrometria de absorção eletrônica (UV-Vis), equilíbrio tautomérico, formação do íon enolato; isomeria cis-trans, grupos orgânicos cromóforos, propriedades fotoquímicas de compostos

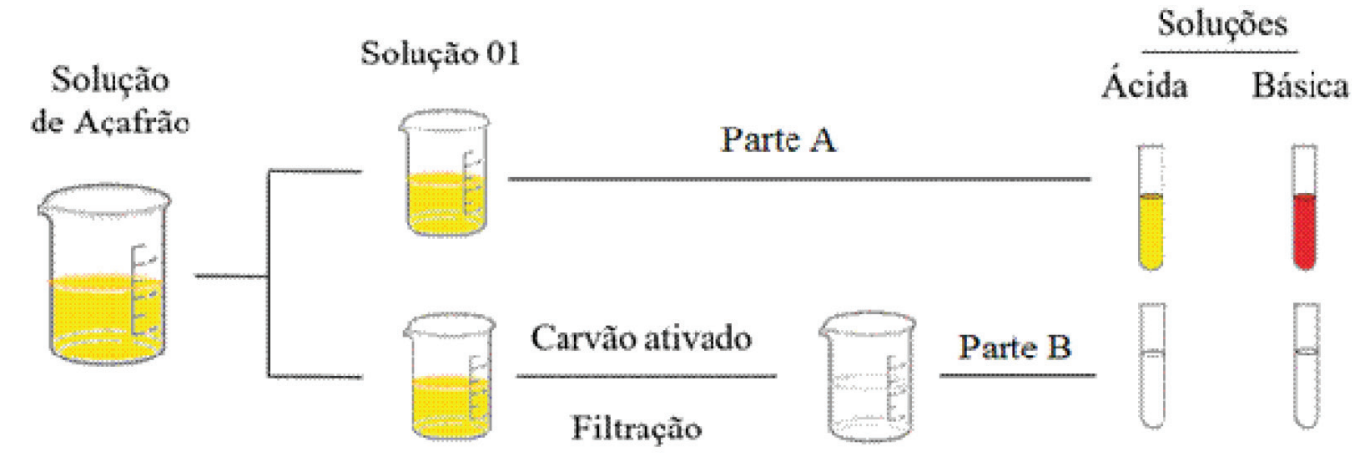

Solução 02

Figura 3. Esquema da preparação de soluções para o teste de indicação de acidez e basicidade 
cromóforos, absortividade molar; lei de Beer-Lambert, rendimento quântico; cálculos de otimização molecular; estudo das contribuições energéticas relativas das formas de ressonância do cromóforo e deslocalização de elétrons $\pi$.

\section{RESULTADOS E DISCUSSÃO}

\section{Discutindo o experimento}

A princípio o uso da solução etanólica de açafrão demonstrou eficácia na indicação de acidez e basicidade das soluções (parte A). A indicação foi observada a partir da mudança de coloração das soluções após adição de gotas do indicador, em que a solução ácida (incolor) tornou-se amarela e a solução básica (incolor) vermelha, conforme descrito na literatura. ${ }^{25,32,46} \mathrm{~A}$ curcumina é um cromóforo orgânico de origem natural, que apresenta em sua estrutura três prótons ionizáveis dispostos nas porções fenólicas e enólica (Figura 4).<smiles>COc1cc(/C=C/C(=O)/C=C(/C=C/c2ccc(Oc3ccccc3)c(OC)c2)Oc2ccccc2)ccc1Oc1ccccc1</smiles>

Figura 4. Prótons ionizáveis da Curcumina

O meio básico, com pH entre 8,5 e 10,5, promoveu a desprotonação da curcumina favorecendo a forma enólica do composto (Figura 5) que apresentou uma coloração vermelha, como observado durante a realização do experimento, com absorção máxima em aproximadamente $463 \mathrm{~nm} .^{20,32,47}$

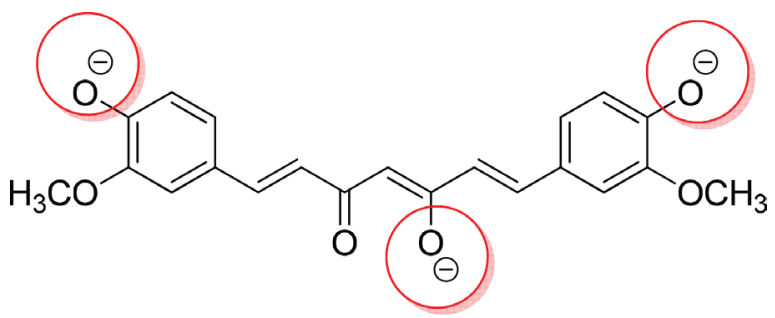

Figura 5. Forma enólica da estrutura da Curcumina

Em meio ácido, com pH entre 1 e 7, foi observado a cor amarela em solução, indicando a presença majoritária do equílibrio cetoenólico (Figura 6), no qual a curcumina apresenta em sua forma neutra contendo os dois grupos $\mathrm{OH}$ fenólicos não ionizados. ${ }^{32,46}$

O segundo momento da experimentação (parte B) propôs comprovar que a curcumina, cromóforo presente na solução etanólica de açafrão é o agente indicador. Para tanto, fez-se uso prévio do carvão ativado com o objetivo de retirar o cromóforo da solução indicadora. A eficiência deste procedimento foi observada a partir da obtenção de uma solução incolor, uma vez que o pó de açafrão utilizado forneceu coloração laranja quando em solução<smiles>COc1ccc(/C=C/C(=O)CC(=O)/C=C/c2ccc3c(c2)OCO3)cc1OC</smiles><smiles>C1=CC=C1</smiles>

neutra inicial. Por fim, a mudança de coloração característica do cromóforo em meios ácidos e básicos não foi observada após adição de gotas da solução 02, de forma que ambas as soluções permaneceram incolores.

Na parte B do experimento, há comprovação que a curcumina é o agente indicador, destacando que compostos cromóforos são essenciais na prática da indicação de soluções ácida e básica. A indicação só ocorre com a presença do cromóforo pois as reações de transferência de prótons entre tais compostos com o ácido ou a base são acompanhadas de modificações estruturais que resultam na alteração ou desaparecimento de grupos cromóforos, interferindo diretamente na radiação eletromagnética que pode ser absorvida por esses compostos e, consequentemente, na sua emissão. ${ }^{47}$

A Figura 7 ilustra os reagentes e alguns dos materiais utilizados no desenvolvimento do experimento.

\section{Discutindo a espectroscopia de absorção eletrônica UV-Vis}

Os estudantes podem observar a retirada do cromóforo da solução não apenas visualmente, mas sim a partir do enfoque químico, utilizando a técnica analítica de espectrofotometria de absorção molecular (UV-Vis). A análise espectroscópica da solução 02 (sem cromóforo) não apresentou absorção na faixa de comprimentos de onda do visível (Figura 8), diferindo da absorção UV-Vis das soluções que contém o cromóforo: solução etanólica do pó de açafrão ( solução 01), que apresentou coloração laranja e absorção máxima no comprimento de onda $420 \mathrm{~nm}$.

Por outro lado, o cromóforo em meio ácido, emitiu cor amarela e apresentou absorção máxima em $341 \mathrm{~nm}$; enquanto o cromóforo em meio básico, na qual a solução possui cor vermelha, apresentou absorção máxima em 434 nm, como demonstrado na Figura 9.

Os comprimentos de ondas observados para as absorções máximas das soluções estudadas estão de acordo com os dados apresentados na literatura, ${ }^{48,49}$ com absorções características para o cromóforo curcumina.

A interação solvente-cromofóro pode interferir diretamente na faixa de absorção apresentada pelo composto. Para o experimento proposto, que fez uso de etanol como solvente, vale resaltar a interação da curcumina em meio neutro com solventes polares, que apresenta absorção máxima característica em 420 nm. Em geral, quando em meio básico aquoso, a curcumina apresenta absorção na faixa de 300 a $500 \mathrm{~nm}$ com máximo em $463 \mathrm{~nm} .{ }^{48}$ Contudo, quando a solução é constituida por um sistema água-etanol em meio básico $(\mathrm{pH} \sim 9,13)$ a absorção máxima passa a ser $434 \mathrm{~nm},{ }^{50}$ como observado no experimento com a análise espectroscópica da solução etanólica do cromóforo em meio básico do experimento.

Em meio ácido e neutro, a curcumina apresenta coloração amarela e sua estrutura em equilíbrio ceto-enólico, em que o tautomerismo pode ser observado. ${ }^{27,38} \mathrm{~A}$ análise espectroscópica realizada com a solução etanólica do cromóforo em meio ácido, utilizada durante o experimento, apresentou absorção na faixa entre 300 e $400 \mathrm{~nm}$ com máximo em $341 \mathrm{~nm}$. O comprimento de onda máximo observado pode ser entendido a partir do estudo da conformação estrutural dos possíveis isômeros da curcumina. $\mathrm{O}$ meio ácido pode favorecer a estrutura $\beta$-dicetona da curcumina, uma vez que a estrutura do cromóforo deixa de apresentar planaridade do isomero cis-enólico,<smiles></smiles>

Figura 6. Equilíbrio ceto-enólico da curcumina 


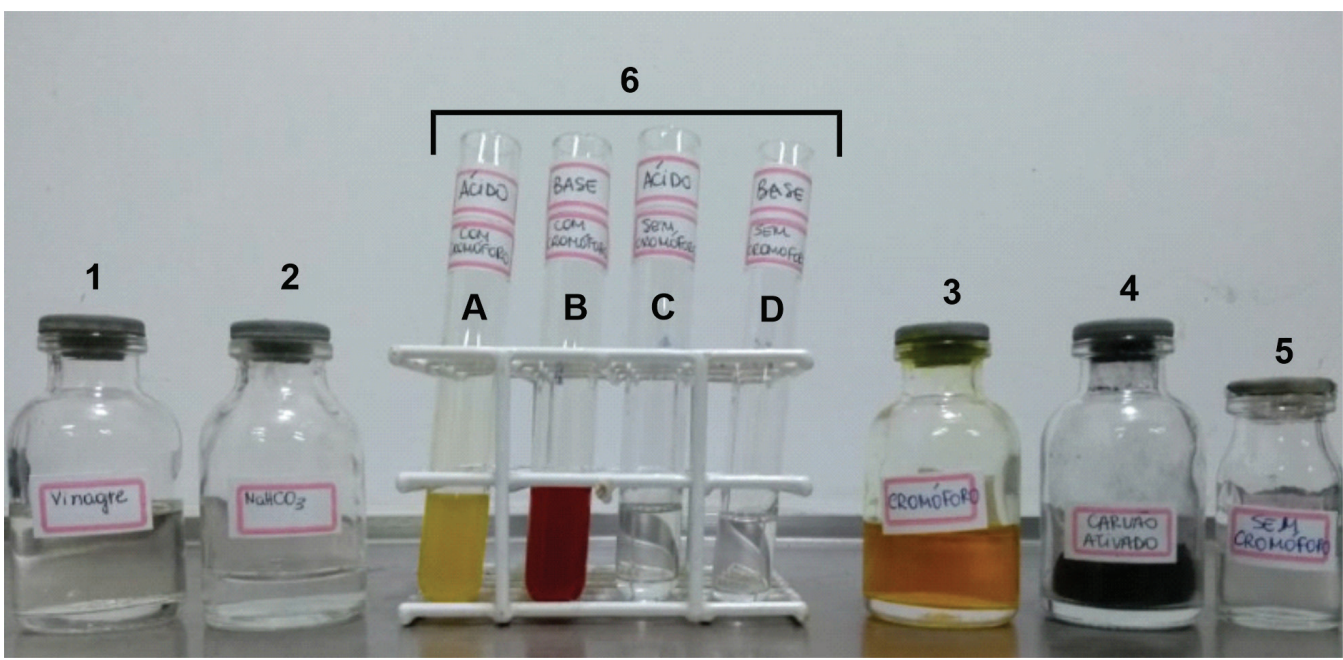

Figura 7. Material utilizado no teste de indicação ácido-base: 1 - Vinagre (solução ácida); 2 - Solução de bicarbonato de sódio comercial (solução básica); 3 - Solução 01 (cromóforo); 4 - Carvão ativado; 5 - Solução 02 (sem cromóforo); 6 - Soluçães ácidas e básicas (A e B com cromóforo e C e D sem cromóforo)

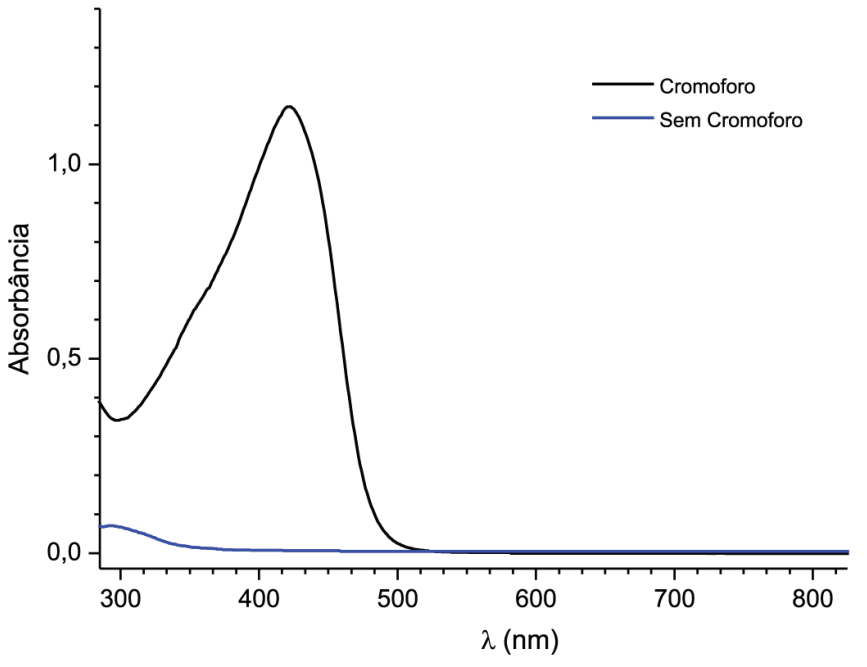

Figura 8. Espectro de absorção eletrônica UV-Vis das soluções 01 (com cromóforo) e 02 (sem cromóforo)

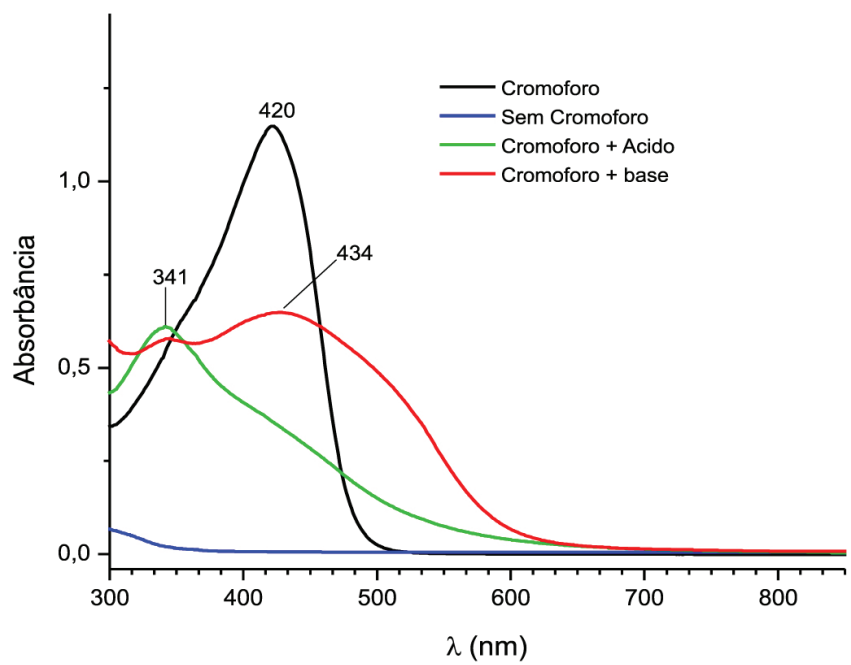

Figura 9. Espectro de absorção eletrônica UV-Vis das soluções 01 e 02 , soluções do cromóforo em meio ácido e em meio básico

e passa a possuir uma torção angular característica da forma mais estavel para a $\beta$-dicetona (Figura 10), a qual pode ser observada a quebra da longa conjugação de eletrons $\pi$ do composto, ou seja, a absorção máxima passa a ser localizada na região do ultravioleta próximo (380 à $200 \mathrm{~nm}){ }^{51}$<smiles>COc1ccc(/C=C/C(=O)CC(=O)/C=C/c2ccc(OC)c(OC)c2)cc1O</smiles>

Forma $\beta$-dicetona

Figura 10. Isômero $E$ - $\beta$-dicetona da curcumina

\section{Discutindo o estudo teórico dos espectros UV-Vis}

Na modelagem computacional do equilíbrio ceto-enólico do cromofóro curcumina, verificamos uma boa concordância com o experimento, visto que na forma enólica (Figura 11) o comprimento de absorção máxima fica em torno de 435,58 nm, enquanto que na forma cetônica (Figura 12) o comprimento de absorção máxima é deslocado para comprimento de onda menores.

De acordo com o modelo teórico há comprovação que o meio ácido favorece a forma cetônica da curcumina, uma vez que no

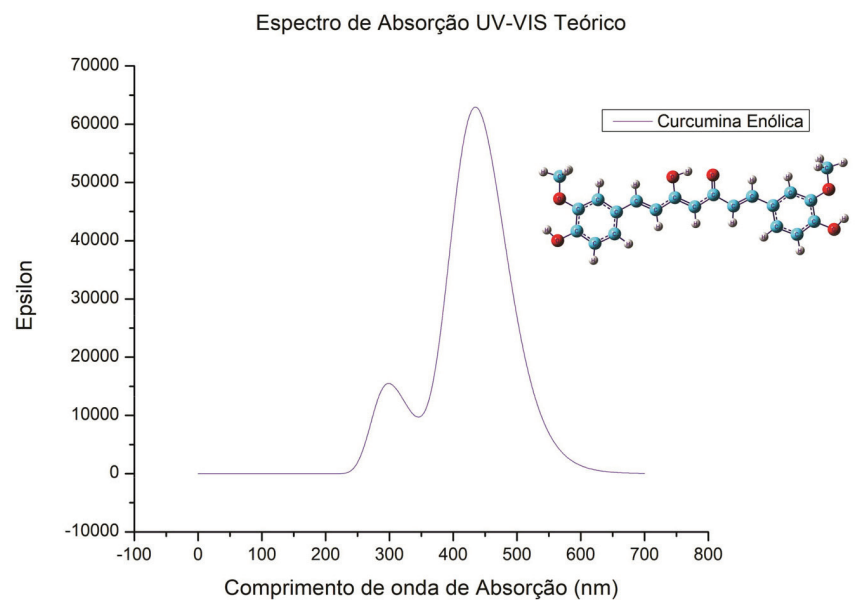

Figura 11. Espectro UV-Vis teórico da curcumina em sua forma enólica 
Espectro UV-VIS Teórico

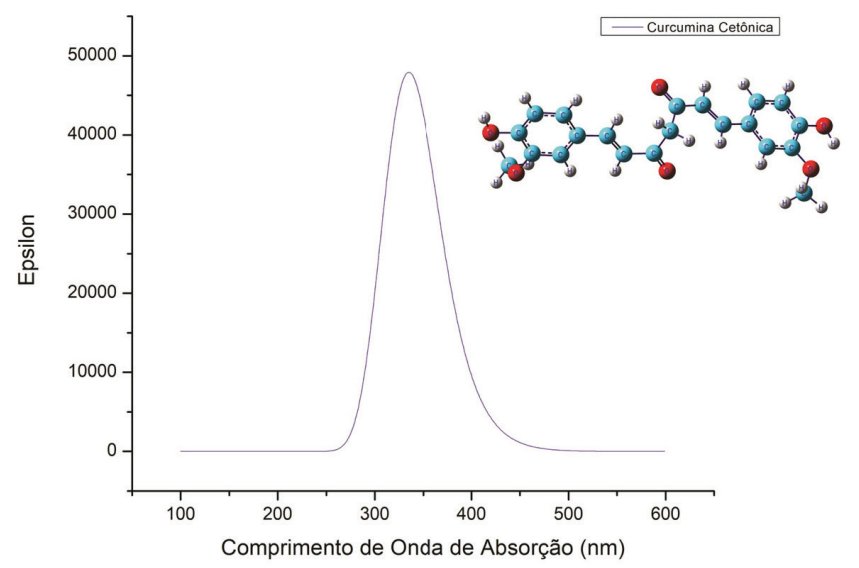

Figura 12. Espectro UV-Vis teórico da curcumina em sua forma cetônica

experimento o comprimento de absorção foi na faixa 300-400 $\mathrm{nm}$, enquanto o valor da absorção máxima observado no modelo teórico foi de $379,13 \mathrm{~nm}$, o que estar em concordância com a faixa de absorção do experimento realizado em meio acido. $\mathrm{O}$ mesmo ocorre com os resultados da modelagem computacional para a forma enólica, onde pode-se observar que a mesma faixa de abssorção é contemplada no estudo teórico e no estudo experimental, confirmando a forma enólica da curcumina é majoritária em $\mathrm{pH}$ básico.

A semelhança entre os dois estudos, teórico e experimental, além de demonstrar confiabilidade do método computacional empregado, indica a possibilidade de desenvolver abordagens teórico-experimentais para o estudo da espectroscopia dos compostos orgânicos e/ou inorgânicos, de maneira acessível tanto experimentalmente quanto computacionalmente, a fim de garantir a abordagem de conteúdos importantes da química orgânica, analítica, inorgânica e da físico-química, de forma interativa com a interrelação de conhecimentos da química computacional, que tem sido pouco explorada nos cursos de graduação em química.

\section{Discutindo os conteúdos abordados no experimento}

A experimentação no ensino de química, no geral, leva a três tipos básicos de resposta: a) a de aspecto epistemológico, a qual admite que a experimentação serve para validar a teoria, revelando a visão tradicional de ciências; b) a de aspecto cognitivo, a qual supõem que as atividades experimentais podem simplificar o entendimento do assunto; c) e a de aspecto moto-vocacional, a qual pressupõe que as aulas práticas ajudam a despertar o interesse e/ou curiosidade pelo estudo.

Mediante o exposto, diversos conteúdos em diferentes áreas do ensino de química foram abordados a partir do desenvolvimento deste experimento, de modo a contribir com a melhoria do processo de ensino e e da aprendizagem. Na química analítica: indicadores ácido-base e potencial hidrogeniônico; conhecimentos acerca de técnicas e aparelhos analíticos, a exemplo espectrofometria de absorção molecular (UV-Vis), para identificar a presença do cromóforo em solução; e o uso do peagâmetro, na identificação precisa do $\mathrm{pH}$ das soluções utilizadas. Na química orgânica: equilíbrio tautomérico, uma vez que a mudança do $\mathrm{pH}$ do meio interfere diretamente a estrutura majoritaria da curcumina em solução; formação do íon enolato; isomeria cis-trans, a partir da variação de conformações estruturais que a curcumina pode apresentar; grupos orgânicos cromóforos; além de possibilitar a análise de espectros de absorção molecular (UV-Vis) de composto orgânico. Na química inorgânica: propriedades fotoquímicas de compostos cromóforos, em meio neutro, ácido e básico; absortividade molar; lei de BeerLambert. Na físico-química: rendimento quântico; cálculos de otimização molecular; estudo das contribuições energéticas relativas das formas de ressonância do cromóforo; análise dos espectros de absorção molecular (UV-Vis) das formas do cromóforo em meio ácido e básico para determinar se essa perda de planaridade e consequente redução da deslocalização de elétrons $\pi$ na estrutura do composto pode interferir na absorção e cores correspondentes a cada solução, Gaussian 09, Gaussian 16, Gauss View, Gamess e WebMol.

Os conteúdos citados são alguns exemplos da versatilidade que o experimento proposto e desenvolvido apresentou, podendo ser realizado individualmente pelas áreas específicas do ensino de química. Contudo, a integralização de tais áreas, a depender do objetivo do professor, pode ser realizada fazendo uso do experimento utilizando uma abordagem multi ou interdisciplinar. De toda forma, o experimento é disposto não para encorajar a visão de estudantes e professores que entendem a experimentação no ensino de química de modo simplista como demonstração empírica de teorias, mas para exemplificar que a experimentação é uma ferramenta multifacetada e necessária para o enriquecimento da aprendizagem nos cursos de química. ${ }^{52-54}$ Por outro lado, os resultados obtidos neste trabalho demonstraram que com a utilização de experimento no ensino de química orgânica, foi observada uma maior aproximação e interesse dos estudantes pela disciplina, uma vez que se associou teoria e prática, e estas com o cotidiano dos estudantes.

\section{CONCLUSÕES}

O experimento proposto e desenvolvido além de ser utilizados apenas materiais de fácil acesso e baixo custo, não fez uso de reagentes de alta toxicidade o que facilitou a limpeza e o descarte. Apresentou de forma simples, a aplicação de um cromóforo natural, utilizado popularmente como tempero caseiro, como indicador ácido-base e a comprovação da sua eficiência, o qual é responsável pela indicação. Ademais, pode ser realizado de forma a correlacionar as diferentes áreas da química ou de forma individual pelas disciplinas, abordando dificuldades distintas a depender do conteúdo explorado.

A química computacional por sua vez se mostrou ser uma ferramenta bastante útil para descrever propriedades químicas dos sistemas, uma vez que seu poder de predição e elucidação de fenômenos se tornam cada vez mais eficientes com o desenvolvimento de computadores mais sofisticados e métodos mais exatos. A teoria do funcional da densidade, mais especificamente o funcional B3LYP, o modelo de solvatação implícita SMD e a metodologia TD-DFT para cálculos de espectros eletrônicos apresentaram boa concordância com os dados experimentais nesse estudo e naqueles já consolidados na literatura. Por isso, a modelagem teórica vinculada a prática experimental se apresenta como importante ferramenta no ensino de graduação, pois possibilita a abordagem de conceitos das diversas áreas da química através do uso de recursos da química conceitual, prática e computacional.

O experimento pode ser executado tanto em laboratórios como demonstrado em salas de aula para uma abordagem sobre indicadores ácido-base, conceito de $\mathrm{pH}$, inclusive como técnica para determinação de $\mathrm{pK}$ no ensino superior através de espectrofotometria de absorção molecular UV-visível. Ao realizar o experimento de forma total ou parcial, o estudante executa uma série de operações importantes na química (tais como, extração, filtração, medição de $\mathrm{pH}$, espectroscopia e interpretação dos resultados), as quais associadas ao conhecimento recebido sobre propriedades ácido-base permitem sua compreensão, funcionando como um processo complementar no entendimento e construção de conceitos. 


\section{AGRADECIMENTOS}

Os autores agradecem à CAPES e FACEPE, pelas bolsas de pós-graduação e incentivos a pesquisa. Ao Laboratório Multiusuário de Análises Químicas (LABMAQ - UFRPE), pela análise espectroscópica de absorção eletrônica UV-Vis, aos Laboratório de Ecoquímica e Síntese (LEQS - UFRPE) e Laboratório de Química Teorica (LAQTEO - UFRPE) onde foram realizados o experimento e os cálculos computacionais, respectivamente.

\section{REFERÊNCIAS}

1. Wei, B.; Liu, H.; Chem. Educ. Res. Pract. 2018, 19, 452.

2. Cunha, S.; Iunes, C. E. M.; Oliveira, C. C.; Santana, L. L. B.; Quim. Nova 2015, 38, 1125.

3. Cunha, S.; Santana, L. L. B.; Quim. Nova 2012, 5, 642.

4. http://apps-webofknowledge.ez19.periodicos.capes.gov.br, acessada em Agosto 2020.

5. Terci, D. B. L.; Rossi, A. V.; Quim. Nova 2002, 25, 684.

6. Couto, A. B.; Ramos, L. A.; Cavalheiro, T. G.; Quim. Nova 1998, 21, 221.

7. Brenner, R. K.; Hess, K. R.; Morford, J. L.; J. Chem. Educ. 2015, 92, 1705.

8. Pinheiro, M. H. T.; De Lima, W. N.; Eclet. Quím. 1999, $24,1$.

9. Kusmawan, U.; Afnidar; Srihamda; Sunarsih, D.; $3^{\text {rd }}$ International Conference on Education 2017, 3, 137.

10. Uchôa, V. T.; Carvalho Filho, R. S. M.; Lima, A. M. M.; Assis, J. B.; Holos 2016, 2, 152.

11. Chavan, M. H.; Shirodkar, P.; Dhake, A. S.; Jadhav, A. G.; Indo Am. J. Pharm. Sci. 2017, 4, 4078

12. Adusei, E. B. A.; Adosraku, R. K.; Oppong-Kyekyeku, J.; Amengor, C. D. K.; Int. J. Anal. Chem. 2019, 2019, 4061927.

13. Kurek, M.; Hlupic, L.; Scetar, M.; Bosiljkov, T.; Gali, K.; J. Food Sci. 2019, 84, 2490.

14. Moradi, M.; Tajik, H.; Almasi, H.; Forough, M.; Ezati, P.; Carbohydr. Polym. 2019, 222, 115030.

15. Shukla, V.; Kandeepan, G.; Vishnuraj, M. R.; Soni, A.; Agric. Res. 2016, 5, 205.

16. Tang, B.; He, Y.; Liu, J.; Zhang, J.; Li, J.; Zhou, J.; Ye, Y.; Wang, J.; Wan, X.; Dyes Pigm. 2019, 170, 107643.

17. Darvesh, A. S.; Aggarwal, B. B.; Bishayee, A.; Curr. Pharm. Biotechnol. 2012, 13, 218.

18. Abourashed, E. A.; Antioxidants 2013, 2, 309.

19. Banerjee, S.; Rajamani, P.; Nat. Prod. 2013, 71, 2175.

20. Benassi, E.; Spagnolo, F.; Theor. Chem. Acc. 2009, 124, 235.

21. Dutta, A.; Boruah, B.; Saikia, P. M.; Dutta, R. K.; J. Mol. Liq. 2013, 187, 350.

22. Tennesen, H. H.; Karlsen, J.; Adhikary, S. R.; Pandey, R.; Z. Lebensm. Unters. Forsch. 1989, 189, 116.

23. Manolova, Y.; Deneva, V.; Antonov, L.; Drakalska, E.; Momekova, D.; Lambov, N.; Spectrochim. Acta, Part A 2014, 132, 815 .

24. Priyadarsini, K. I.; J. Photochem. Photobiol., C 2009, 10, 81.

25. Wang, Y.-J.; Pan, M.-H.; Cheng, A.-L.; Lin, L.-I.; Ho, Y.-S.; Hsieh, C.Y.; Lin, J.-K.; J. Pharm. Biomed. Anal. 1997, 15, 1867.

26. Breedlov, C. H.; J. Chem. Educ. 1995, 72, 540.

27. Sueth-Santiago, V.; Mendes-Silva, G. P.; Decoté-Ricardo, D.; de Lima, M. E. F.; Quim. Nova 2015, 38, 538 .
28. Kumar, N.; Sakhya, S. K.; Int. J. Pharm. Sci. Res. 2012, 41, 103.

29. Patil, N. B.; Patil, A. A.; Patil, K. B.; Wagh, M. N.; EPRA Int. J. Res. Dev. 2018, 3, 138 .

30. Dias, M. V.; Guimarães, P. I. C.; Merçon, F.; Quim. Nova Esc. 2003, 171, 27.

32. Priyadarsini, K. I.; Molecules 2014, 19, 20091.

33. Francesco, D. P.; Giuliana, R.; Eleonora, A. D. M.; Giovanni, A.; Federico, F.; Stefano, T.; J. Pain Res. 2013, 6, 201.

34. Fagundes, T. S. F.; Dutra, K. D. B.; Ribeiro, C. M. R. R.; Epifanio, R. A.; Valverde, A. L.; J. Chem. Educ. 2016, 93, 326.

35. Supharoek, S.-A.; Ponhong, K.; Siriangkhawut, W.; Grudpan, K.; J. Food Drug Anal. 2018, 26, 583.

36. Koch, W.; Holthausen, M. C.; A Chemist's Guide to Density Functional Theory, $2^{\text {nd }}$ ed., Wiley-VCH: Weinheim, 2001.

37. Stephens, P. J.; Devlin, J. F.; Chabalowski, C. F.; Frisch, M. J.; J. Phys. Chem. 1994, 98, 11623.

38. Hariharan, P. C.; Pople, J. A.; Theor. Chim. Acta 1973, 28, 213.

39. Pople, J. A.; Scott, A. P.; Wong, M. W.; Radom, L.; Israel J. Chem. 1993, 33, 345.

40. Cramer, C. J.; Truhlar, D. G.; Chem. Rev. 1999, 99, 2161.

41. Runge E.; Gross, E. K. U.; Phys. Rev. Lett. 1984, 52, 997.

42. Adamo, C.; Jacquemin, D.; Chem. Soc. Rev. 2013, 42, 845.

43. Dennington, R.; Keith, T. A.; Millam, J. M.; Semichem Inc., Shawnee Mission, KS, GaussView, Version 6.1, 2016.

44. Frisch, M. J.; Trucks, G. W.; Schlegel, H. B.; Scuseria, G. E.; Robb, M. A.; Cheeseman, J. R.; Scalmani, G.; Barone, V.; Mennucci, B.; Petersson, G. A.; Nakatsuji, H.; Caricato, M.; Li, X.; Hratchian, H. P.; Izmaylov, A. F.; Bloino, J.; Zheng, G.; Sonnenberg, J. L.; Hada, M.; Ehara, M.; Toyota, K.; Fukuda, R.; Hasegawa, J.; Ishida, M.; Nakajima, T.; Honda, Y.; Kitao, O.; Nakai, H.; Vreven, T.; Montgomery, J. A.; Peralta, J. E.; Ogliaro, F.; Bearpark, M.; Heyd, J. J.; Brothers, E.; Kudin, K. N.; Staroverov, V. N.; Kobayashi, R.; Normand, J.; Raghavachari, K.; Rendell, A.; Burant, J. C.; Iyengar, S. S.; Tomasi, J.; Cossi, M.; Rega, N.; Millam, J. M.; Klene, M.; Knox, J. E.; Cross, J. B.; Bakken, V.; Adamo, C.; Jaramillo, J.; Gomperts, R.; Stratmann, R. E.; Yazyev, O.; Austin, A. J.; Cammi, R.; Pomelli, C.; Ochterski, J. W.; Martin, R. L.; Morokuma, K.; Zakrzewski, V. G.; Voth, G. A.; Salvador, P.; Dannenberg, J. J.; Dapprich, S.; Daniels, A. D.; Farkas, Ö.; Foresman, J. B.; Ortiz, J. V.; Cioslowski, J. Fox, D. J.; Gaussian 09, Gaussian, Inc., Wallingford, CT, 2009.

45. Schmidt, M. W.; Baldridge, K. K.; Boatz, J. A.; Elbert, S. T.; Gordon, M. S.; Jensen, J. H.; Koseki, S.; Matsunaga, N.; Nguyen, K. A.; Su, S.; Windus, T. L.; Dupuis, M.; Montgomery Jr., J. A.; J. Comput. Chem. 1993, 14, 1347.

46. Khopde, S. M.; Priyadarsini, K. I.; Palit, D. K.; Mukherjee, T.; Photochem. Photobiol. 2000, 72, 625.

47. Soltan, M. E.; Sirry, S. M.; J. Chin. Chem. Soc. 2002, 49, 63.

48. Tonnesen, H. H.; Karlsen, J.; Z. Lebensm. Unters. Forsch. 1985, 180, 402.

49. Zhao, Q.; Kong, D.-X.; Zhang, H. Y.; Nat. Prod. Commun. 2008, 3, 229.

50. Shen, L.; Ji, H. F.; Spectrochim. Acta, Part A 2007, 67, 619.

51. Galiazzi, M. C.; Goncalves, F. P.; Quim. Nova 2004, 27, 326.

52. Gonçalves, F. P.; Marques, P. A.; Quim. Nova 2012, 35, 837.

53. Gonçalves, F. P.; Marques, P. A.; Quim. Nova 2011, 34, 899.

54. de Souza, R. F.; Oliveira, P. F.; Queiroz., S. L.; Alexandria: Revista de Educação em Ciência e Tecnologia 2018, 12, 93. 